\title{
Effect of Dietary Methionine to Cysteine Ratio on In- flammatory Responses in Chicks with Multiple Injections of Escherichia coli Lipopolysaccharide
}

\author{
Kazuaki TAKAHASHI and Yukio AKIBA \\ Faculty of Agriculture, Tohoku University, Aoba-ku, Sendai-shi 981-8555, Japan
}

(Received March 26, 1999 : Accepted June 15, 1999)

\begin{abstract}
Effects of dietary methionine (Met) and cysteine (Cys) on plasma interleukin-1 (IL-1) like activity and alphal-acid glycoprotein (AGP) concentration were studied in chicks injected repeatedly with Escherichia coli lipopolysaccharide (LPS). Male broiler chicks fed a Met $(0.62 \%)$ - or Cys $(0.62 \%)$-rich diet $(0.94 \%$ of sulphur amino acid content in diets) were daily injected intraperitoneally with LPS at levels of 0.25 or $1 \mathrm{mg}$ per $\mathrm{kg}$ body weight over 13 days. The highest AGP concentration in plasma was found on day 1 or 2 of LPS injections, and thereafter the concentration decreased by day 4. On days 1 and 2, plasma AGP concentration in chicks received $1 \mathrm{mg}$ of LPS was higher than that in chicks injected with $0.25 \mathrm{mg}$ of LPS in both dietary groups. Plasma AGP concentration in the Met rich diet fed chicks was higher than that in the Cys-rich diet fed group on days 6 and 14 in the $0.25 \mathrm{mg}$ LPS injected group. The Cys-rich diet fed chicks had greater plasma AGP concentration than the Met-rich diet fed group on day 1 in the $1 \mathrm{mg}$ LPS injected group. The highest IL-1 like activity in plasma was found on day 2 and thereafter the activity decreased by day 4 in all groups. The IL-l like activity in chicks fed the Cys-rich diet was greater than that in chicks fed the Met-rich diet on day 1 in the $0.25 \mathrm{mg}$ LPS injected group and on day 2 in $1 \mathrm{mg}$ LPS injected group. On days 4, 10 and 14, chicks fed the Met-rich diet had higher IL-1 like activity than chicks fed the Cys-rich diet in the $1 \mathrm{mg}$ LPS injected group. The results confirmed that ratio of Met to Cys in diet is a modulator of inflammtory response to LPS in chicks. The results also suggested that the higher inflammtory responses of chicks fed the Cys-rich diet to the higher dose of LPS is temporary, and chicks fed the Met-rich diet have almost similar or higher sensitivity to repeated injection of LPS compared with chicks fed the Cys-rich diet.

Animal Science Journal 70 (5) : 312-318, 1999
\end{abstract}

Key words : Repeated injection of LPS, Inflammatory response, Dietary Met and Cys, Chicks

Cysteine (Cys) or sulphur amino acid (SAA) is of prime importance in increasing liver glutathione $(\mathrm{GSH})$, zinc and protein content in rats treated with tumor necrosis factor (TNF)- $\alpha^{11,12)}$. Dietary sulfur amino acids also have certain influence on inflammatory and immune responses. Chicks fed on a methionine (Met) sufficient diet had higher interleukin (IL)- 1 activity, growth rate and feed intake compared to chicks fed on a Met-deficient diet when they were received immunogen injections ${ }^{13)}$. Tsiagbe et $a l^{23)}$ showed that antibody production against sheep red blood cell and delayed hypersensivity against phytohemagglutinin (PHA)-P in chicks fed a SAAdeficient diet was lower than those in chicks fed a SAA-sufficient diet.

Although Hunter et al. ${ }^{(2)}$ showed production of several acute phase proteins in rats fed a Met-rich diet did not differ from that in rats fed on a Cys-rich diet when they were injected with TNF- $\alpha$, it is likely that the function of Cys under stressful conditions is possibly different from that of Met. Tsiagbe et al. ${ }^{22)}$ showed that Cys was $70-84 \%$ as efficient as Met in enhancing

Correspondence : Kazuaki TAKAHASHI (fax : +81 (0) 22-717-8691, e-mail : taka@bios.tohoku.ac.jp) 
immunoglobulin- $\mathrm{G}$ ( $\mathrm{IgG}$ ) production and in delaying hypersensitivity to PHA-P stimulation, respectively, indicating that $\mathrm{Cys}$ is an essential nutrient for potentiating the immune response in broilers. Feeding L-Cys increases tissue GSH level ${ }^{9 \text {, }}$, and an increase in tissuc GSH concentration may be beneficial for growth of chicks reared in conditions with immunological stress by drug adminstration ${ }^{2)}$. Furthermore, Cys and Cys derivatives have been shown to modulate lymphocyte and macrophage functions in the in vitro studies ${ }^{6}$. Takahashi et al. ${ }^{20)}$ indicated that a high Cys diet enhanced plasma alpha 1-acid glycoprotein (AGP) concentration, IL-1 like activity when chicks were single injected with Escherichia coli lipopolysaccharide (LPS), and lymphocyte proliferation. Thus, a change in the ratio of Cys and Met in diet has an impact on the immune and inflammatory responses in chickens. However, modulatory effect of nutrients on immune and inflammatory responses would be changed since stress intensity and duration affected the extent of these responses in rats ${ }^{8,17)}$ and in chicks ${ }^{19,21)}$. The purpose of this study was to determine how multiple injection of Escherichia coli LPS affects inflammatory responses, assessed by plasma AGP concentration and IL-1 like activity, in chicks fed diets containing different ratio of Cys and Met within the SAA requirement recommended by the Feeding Standard ${ }^{15)}$.

\section{Materials and Methods}

Male broiler chicks were housed in a battery brooder with electric heater and fed a commercial broiler starter diet until 7 days of age, and forty eight chickens of almost uniform body weight were selected. They were randomly assigned to six groups of 8 chicks.

Two nutritional groups were set and the chicks were fed ad libitum for 21 days diets supplemented with either $0.37 \%$ Met or Cys to a diet on a weight basis (giving a total in each case of $0.94 \% \mathrm{SAA} / \mathrm{kg}$ diet, which is recommended by the NRC Feeding Standard, 1984) ${ }^{15)}$. A Met- or Cys-rich diet consisted of $57.74 \%$ corn, $25.52 \%$ soybean meal, $3.50 \%$ soy protein, $5.10 \%$ soybean oil, $1.80 \%$ calcium phosphate, $1.23 \%$ calcium carbonate, $0.29 \%$ sodium chloride,
$0.15 \%$ L-lysine, $0.08 \%$ L-threonine, $0.14 \% \quad \mathrm{~L}$ arginine, $4.28 \%$ L-glutamic acid, $0.4 \%$ mineral and vitamin mixture" and $0.37 \%$ of L-methionine or Lcysteine per $\mathrm{kg}$ diet. Calculated metabolizable energy and crude protein content in the experimental diets were $3,200 \mathrm{kcal}$ and $22.0 \%$, respectively.

At 14 days of age, eight chicks of each dietary group were intraperitoneally injected with $0,0.25$ or $1 \mathrm{mg} / \mathrm{kg}$ BW of Escherichia coli LPS (0111 : B4, Sigma) for 13 days daily. The LPS was dissolved in stcrilized saline and the remaining 8 chicks were injected with sterilized saline $(0.9 \%$ sodium chloride). Blood sample was obtained from wing vein just before injection of LPS on days $0,1,2,4,6,8,10$ and 14 following the commencement of LPS injection.

Plasma samples from 2 chicks were provided for the determination of IL- 1 like activity as described previously ${ }^{21}$. The method of determination of AGP concentration in individual plasma was described in our previous report ${ }^{18)}$. A 2 (dietary treatment) $\times 3$ (the LPS injection procedure) factorial experimental test was applied to analyze body weight gain, feed intake, and feed efficiency and the calculation was carried out using the General Linear Model of SAS (SAS institute, Cary NC, USA). Data from plasma IL-1 like activity and AGP concentration after carrying out LPS treatments were subjected to the repeated measures analysis of variance using the General Linear Model of SAS (SAS institute, Cary NC, USA). Dietary treatment and LPS level were whole plots and times of LPS injection (sampling time) was sub-plot. Means of plasma IL-1 like activity and AGP concentration were separated by Tukey's test between dietary treatments at each sampling time without the control group (the saline injected group). Dunnett test was also applied to determine the difference between means of plasma IL-1 like activity and AGP concentration on days 1 to 14 and means on day 0 in each dietary treatment.

\section{Results}

Table 1 shows body weight gain, feed intake and feed efficiency during 14 days from 14 days of age. Daily injections of LPS at 0.25 and $1 \mathrm{mg} / \mathrm{kg}$ body weight and dietary SAA did not affected body weight 
Table 1. Effectes of dietary Met and Cys on feed intake, body weight gain and feed efficiency in repeated LPS injected-chicks

\begin{tabular}{ccccc}
\hline Diet & $\begin{array}{c}\text { LPS } \\
(\mathrm{mg} / \mathrm{kg} \mathrm{BW})\end{array}$ & $\begin{array}{c}\text { Feed intake }^{1)} \\
(\mathrm{g} / 14 \text { days })\end{array}$ & $\begin{array}{c}\text { Body weight } \\
\text { gain }^{2} \\
(\mathrm{~g} / 14 \text { days })\end{array}$ & $\begin{array}{c}\text { Feed } \\
\text { efficiency } \\
(\%)\end{array}$ \\
\hline \multirow{3}{*}{ Met } & 0 & $1,075 \pm 20$ & $638 \pm 41$ & $59.2 \pm 1.8$ \\
& 0.25 & $1,056 \pm 17$ & $624 \pm 24$ & $59.1 \pm 2.9$ \\
& 1.00 & $1,086 \pm 21$ & $645 \pm 41$ & $59.3 \pm 1.8$ \\
\multirow{2}{*}{ Cys } & 0 & $1,076 \pm 34$ & $626 \pm 27$ & $58.3 \pm 0.7$ \\
& 0.25 & $1,138 \pm 68$ & $635 \pm 36$ & $56.6 \pm 1.5$ \\
& 1.00 & $1,107 \pm 27$ & $648 \pm 41$ & $58.4 \pm 2.6$ \\
\hline${ }^{17}$ Mean \pm SE (8 observations). & ${ }^{2)}$ Mean \pm SE (4 observations). &
\end{tabular}

Table 2. Repeated measures analysis of variance of plasma IL-1 like activity and $\alpha 1$-acid glycoprotein concentration

\begin{tabular}{llcc}
\hline \multirow{2}{*}{ Subject } & \multicolumn{2}{c}{ IL-1 activity $\alpha 1$ 1-acid glycoprotein } \\
\cline { 3 - 4 } & Diet & \multicolumn{2}{c}{ Probability $>$ F } \\
\hline \multirow{2}{*}{ Whole plot $^{1)}$} & LPS & 0.6573 & 0.2063 \\
& Diet $\times$ LPS & 0.1554 & 0.3122 \\
& Time & 0.0902 & 0.0419 \\
\hline \multirow{2}{*}{ Sub plot ${ }^{2)}$} & Time $\times$ Diet & 0.0083 & 0.0387 \\
& Time $\times$ LPS & 0.0070 & 0.0446 \\
& Time $\times$ LPS $\times$ Diet & 0.0112 & 0.0202 \\
\hline
\end{tabular}

1) Tests of hypotheses for between subjects effects.

2) Univariate tests of hypotheses for whthin subjects effects.

gain, feed intake and feed efficiency for 14 days. The significant interactive effect of LPS treatment and dietary SAA was also not found.

Table 2 shows probability of repeated measures analysis of variance in plasma IL-1 like activity and AGP concentration using split-plot model analysis after treating with LPS. The result showed that diet and LPS level, frequency of LPS injection and the interaction among the frequency and the other factors were highly significant. This suggests that frequency and level of LPS injection predominantly affects plasma IL-1 like activity and AGP concentration and dietary Cys to Met ratio have influence on these parameters when LPS was injected.

Only data of plasma IL-1 like activity and AGP concentration in the LPS injected chicks were shown in the figures because multiple injection of the saline did not significantly affect the activity and concentration.

Figure 1 shows changes in plasma AGP concentration by daily injection of $0.25 \mathrm{mg}(\mathrm{A})$ and $1 \mathrm{mg}(\mathrm{B})$ LPS per $\mathrm{kg}$ body weight in chicks fed the Met- and Cys-diet. The highest AGP concentration in plasma was found on day 1 or 2 of LPS injection, thereafter the concentrations decreased by day 4 followed by small increases in chicks fed the both diets. On days 1 and 2, plasma AGP concentration in chicks received $1 \mathrm{mg}$ of LPS was higher than that in chicks injected with $0.25 \mathrm{mg}$ of LPS. Plasma AGP concentration in the Met-diet fed group was higher than that in the Cys-diet fed group on days 6 and 14 in chicks injected daily with $0.25 \mathrm{mg}$ LPS, but the concentration did not 

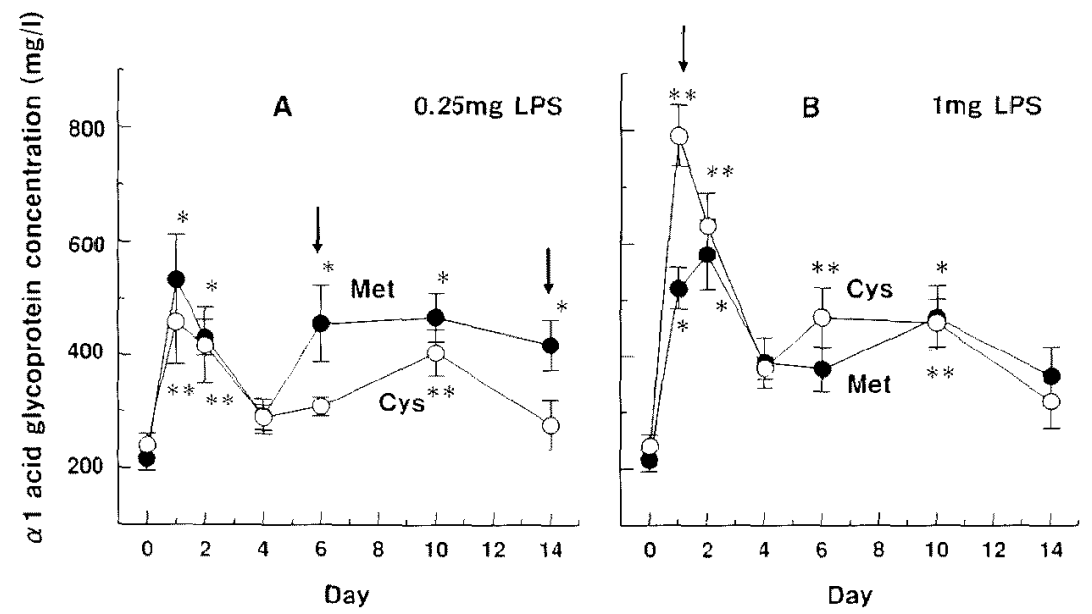

Fig. 1. Changes in plasma $\alpha 1$-acid glycoprotein (AGP) concentration by daily injections of $0.25 \mathrm{mg}$ (A) and $1 \mathrm{mg}$ (B) LPS per $\mathrm{kg}$ body weight over 13 days in chicks fed Met $(\mathbf{O})$ and Cys $(O)$ diet. Values are means with SE of 8 observations. $\downarrow$ Significant difference between the Met diet and the Cys diet in the same sampling day $(\mathrm{P}<0.05)$. * Significant difference in means of plasma AGP concentration on days 1 to 14 to means on day 0 in chicks fed the Met diet $(\mathbf{P}<0.05)$. ** Significant difference in means of plasma AGP concentration on days 1 to 14 to means on day 0 in chicks fed the Cys diet $(\mathrm{P}<$ $0.05)$.

differ on days 1, 2 and 4. The Cys-diet fed group had greater plasma AGP concentration than the Met diet fed group on day 1 in chicks received $1 \mathrm{mg}$ LPS, but the concentration did not differ on days $2,4,6,10$ and 14. In general, plasma AGP concentration was higher in chicks fed the Met-diet than chicks fed the Cys-diet among the $0.25 \mathrm{mg}$ LPS injected group, while no differences were observed in the $1 \mathrm{mg}$ LPS injected groups. The concentrations in the saline injectedchicks on days $1,4,10$ and 14 were within ranges of 215 to $260 \mathrm{mg} / \mathrm{m} l$ in the both dietary groups.

Figure 2 shows changes in plasma IL 1-like activity following daily injections of $0.25 \mathrm{mg}$ (A) and $1 \mathrm{mg}$ (B) LPS per kg body weight in chicks fed the Metand Cys-diet. Fluctuation pattern of IL-1 like activity during 14 days was generally similar as that in AGP concentration. The highest IL-1 like activity in plasma was found on day 2 , and thereafter the concentration was decreased by day 4 in all groups. The Met-diet enhanced the activity on day 14 as high as the activity found on day 1 or 2 . The activity in chicks fed the Cys-diet was higher than that in chicks fed the Met-diet on day 1 in $0.25 \mathrm{mg}$ LPS injected group and day 2 in $1 \mathrm{mg}$ LPS injected group. On days 4, 10 and 14, chicks fed the Met-diet had higher IL-1 like activity than chicks fed the-Cys diet in $1 \mathrm{mg}$ LPS injected-group. The activities in the saline injected-chicks on days 1, 4, 10 and 14 were within 1.05 to 1.25 .

\section{Discussion}

SAA is not only first limiting amino acid for growth and reproduction in a corn-soybean meal based diet of chicks, but also of a great impact on immune and stress responses, 10-13, 16, 20,22,23). Furthermore, ratio of Cys and Met in diet also modifies these responses ${ }^{20,22)}$. The pro-inflammtory cytokines including IL-1 released from macrophages/monocyte are important initiators and regulators of the local immune responses ${ }^{10)}$. AGP produced from liver possibly modulates immune responses such as mitogen induced proliferation, antibody production, capping of Con A receptors and surface immunoglobulin on the lymphoid cell surface in mammals ${ }^{3-5,19)}$. Thus, regulation of IL-1 and acute phase protein such as AGP results in the control of immune response in lympho- 
TAKAHASHI and AKIBA
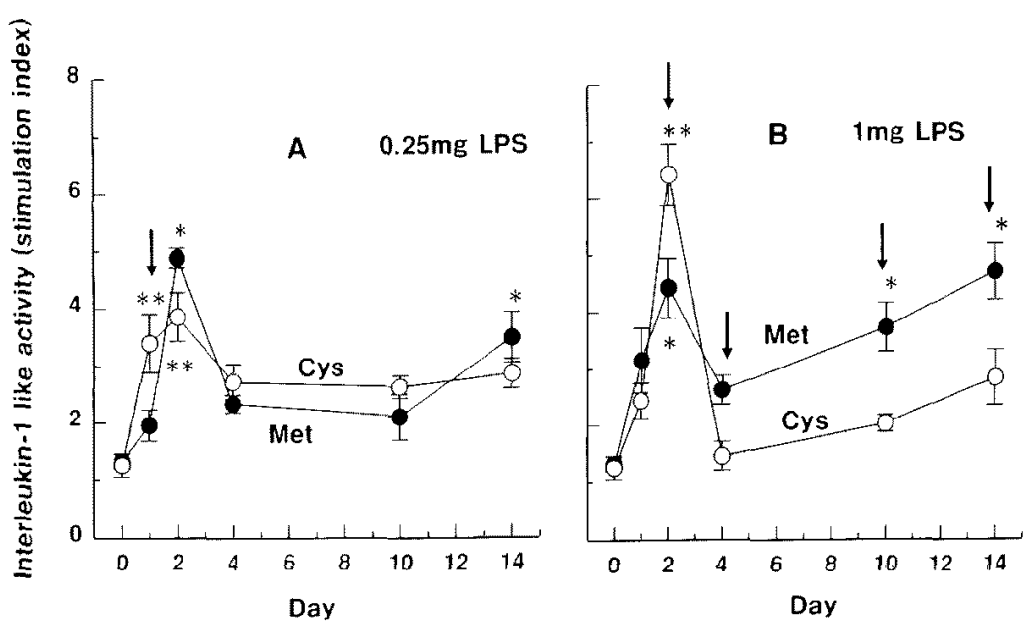

Fig. 2. Changes in plasma $\alpha$ 1-acid glycoprotein (AGP) concentration by daily injections of $0.25 \mathrm{mg}$ (A) and $1 \mathrm{mg}$ (B) LPS per $\mathrm{kg}$ body weight over 13 days in chicks fed Met $(O)$ and Cys $(O)$ diet. Values are means with SE of 4 observations. $\downarrow$ Significant difference between the Met diet and the Cys diet in the same sampling day $(\mathrm{P}<0.05)$. * Significant difference in means of plasma AGP concentration on days 1 to 14 to means on day 0 in chicks fed the Met diet $(\mathbf{P}<0.05)$. ** Significant difference in means of plasma AGP concentration on days 1 to 14 to means on day 0 in chicks fed the Cys diet $(\mathrm{P}<$ $0.05)$.

cytes and pathogen invasiveness. The present results clearly show that early inflammatory responses to LPS in chicks fed the Cys rich diet greater than that in chicks fed the Met rich diet, especially a higher dosage of LPS. Our previous study ${ }^{20)}$ showed that feeding a high Cys diet increased the response of plasma AGP concentration and IL-1 like activity following a single injection of LPS and splenocyte proliferation to Con A. These results suggested that ratio of Cys to Met in diet is a nutritional modulator of certain inflammatory responses as well as n-3 fatty acids, arginine, and vitamin $\mathrm{E}$ as previously recognized ${ }^{10)}$.

Repeated injection or continuous infusion of LPS resulted in decrease of the responses of immune and stress in mammals ${ }^{8,17)}$. In the present experiment, degree of the depressed responses of AGP from day 4 to 14 was greater in chicks fed the Cys rich diet and injected with $0.25 \mathrm{mg}$ LPS (Fig. 1 A) in the present experiment, and the similar responses of IL-1 like activity to $1 \mathrm{mg}$ of LPS injection was observed in chicks fed the Cys rich diet. The responses in chicks fed the Met rich diet gradually increased and nearly became the highest values by daily injection of LPS.
We previously found the similar response of AGP concentration following daily injection of LPS when chicks were given a commercial diet with Met as the main source of $\mathrm{SAA}^{19)}$. Feeding L-Cys increases tissue GSH level ${ }^{9}$, and an increase in tissue GSH concentration may be beneficial for growth of chicks reared in conditions with immunological stress ${ }^{2)}$. Chicks fed the Cys-rich diet had the higher inflammatory responses in early stage of LPS injection, and thereafter the responses were almost similar to chicks fed the Met- and Cys-rich diets. These results suggested that acute immunological stress may be increased demand of Cys to synthesize GSH, which is important to maintain normal immunological functions in the cells, especially macrophage like cell. Therefore, it is likely that dietary Met diet has a potential to maintain immune and/or stress responses rather than Cys under a chronic immuno-stimulation. However, further study needs to clarify whether the high Met content in diet is preferable in sustaining animal health.

In mammals, IL-1, IL-6 and TNF- $\alpha$ are responsible for production of acute phase proteins ${ }^{10)}$, in which 


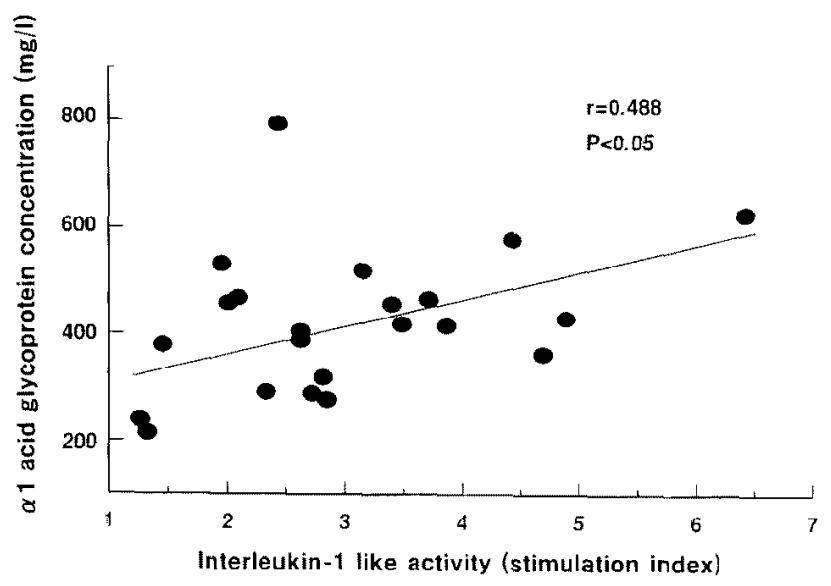

Fig. 3. Relationship between plasma $\alpha 1$-acid glycoprotein concentration and plasma interleukin 1 like activity. Mean values of each dietary treatments $(n=24)$ were provided for the analysis.

IL-6 regulated acute phase protein synthesis in hepatocytes within the cytokine network. Nakamura et al. ${ }^{14\rangle}$ suggested that increase in corticosterone and IL-6 in serum following LPS injection were associated with an increase in the AGP concentration in chicks, but IL- 6 may not be contributed to production of AGP in chicks. Plasma IL-1 like activity was positively correlated with plasma AGP concentration in present study (Fig. 3), suggesting that changes in plasma AGP concentration in chicks are of use as an indicator of IL-1 production or release rather than IL6 in chicks.

Generally, an increase in IL-1 production or release enhances catabolic reactions and decreases growth rate. Our previous experiment showed that single injection of LPS significantly reduced body weight gain, while three times injections of Escherichia coli LPS (0111: B 4) did not affect body weight gain. In the present experiment, 13 times injection of LPS also unaffected body weight gain, feed intake and feed efficiency in chicks fed the Met- or Cys-diet regardless of higher plasma IL-1 like activity especially in the Met-diet fed chicks. Furthermore, we observed that daily injection of LPS $(0.9 \mathrm{mg} / \mathrm{kg}$ body weigh) over 13 days did not affect body weight gain in chicks fed the commercial broiler ration (control group, $632 \pm 26$ $\mathrm{g}$ vs. injection group, $640 \pm 34 \mathrm{~g}$ ) even when plasma AGP concentrations were changed ${ }^{19)}$. A possible ex- planation for this phenomenon might be differences in the serotypes of LPS used. It is, however, likely that the increase in $1 \mathrm{~L}-1$ production or release is not necessarily associated with an reduction of growth in the condition of repeated injection of LPS, although immunostimulation by repeated injection of LPS (0127 : B 8 ) over 9 days resulted in reduction in growth performance $\mathrm{e}^{24)}$.

In conclusion, the ratio of Met to Cys in diet is a modulator of inflammatory response to LPS in chicks, and the higher inflammatory responses of chicks fed the Cys-rich diet to the higher dose of LPS is temporary, and chicks fed the Met-rich diet have almost similar or higher sensitivity to repeated injection of LPS compared with chicks fed the Cys-rich diet. Thus the present study shows that the ratio of Met to Cys in diet has an impact on early inflammatory responses to intensity of immunological stress. The present study showed that responses to inflammatory stress were different from nutrient composition in diet, stress intensity and duration. Since the changes in these responses affect animal performance and health, intensity and duration of stress should be considered as a crucial factor for the determination of nutrient requirement of animals in future.

\section{References}

1) Akiba Y, Mastumoto T. Effect of force-feeding and dietary cellulose on liver lipid accumulation and lipid composition of liver and plasma in growing chicks. Journal of Nutrition, $108: 739-748.1978$.

2) Boebel KP, Baker DH. Blood and liver concentrations of glutathione and plasma concentrations of sulfur-containing amino acids in chicks fed deficient, adequate, or excess levels of dietary cysteine. Proceeding of Society for Experimental Biology and Medicine, $172: 498-501.1983$.

3) Bories PN, Feger J, Benbernou N, Rouzeau J-D, Agneray J, Durand G. Prevention of tri- and tetra antinnary glycans of human alpha 1-acid glycoprotein in release of macrophage inhibitor of interleukin-1 activity. Inflammation, $14: 315^{-323}$ 1990.

4) Cheresh DA, Haynes DH, Distasio JA. Interaction of an acute phase reactant, $\alpha 1$-acid glycoprotein (orosomucoid), with the lymphoid cell surface : A model for non-specific immune reaction. 
Immunology, 5:541-550. 1984.

5) Chiu KM, Mortensen RF, Osmond AP, Gewurz H. Interactions of alpha 1-acid glycoprotein with the immune system. Immunology, 32 : 997-1005. 1977.

6) Droge W, Eck HP, Gmunder H, Mihm S. Modulation of lymphocyte functions and immune responses by cysteine and cysteine derivatives. American Journal of Medicine, $30: 104 \mathrm{~S}-114$ S. 1991.

7) Enkvetechakul B, Bottje WG. Influence of diethylmateate and cysteine on tissue glutathione and growth in broiler chickens. Poultry Science, 74 : 864873. 1995.

8) Friedman H, Newton C, Widen R, Klein T, Spitzer JD. Continuous endotoxin infusion suppresses rat spleen cell production of cytokines. Proceeding of Society Experimental and Biological Medicine, 199 : 360-364. 1992.

9) Graber G, Baker DH. Sulfur amino acid nutrition of the growing chick : quantitative aspects concentrating the efficiency of dietary methionine. Journal of Animal Science, 33 : 1005-1011. 1971.

10) Grimble RF. Dietary manipulation of the inflammatory response. Proceedings of the Nutrition Society, $51: 285-294.1992$.

11) Grimble RF, Jackson AA, persaud C, Wride MJ, Delers $F$, Engler $R$. Cysteine and glycine supplementation modulate the metabolic response to tumor necrosis factor alpha in rats fed a low protein diet. Journal of Nutrition, 122 : 2066-2073. 1992.

12) Hunter EAL, Grimble RF. Cysteine and methionine supplementation modulate the effect of tumor necrosis factor alpha on protein synthesis, glutathione and zinc concentration of liver and lung in rats fed a low protein diet. Journal of Nutrition, 124 : 2319-2338. 1994.

13) Klasing $\mathrm{KC}$, Barnes DM. Decreased amino acid requirements of growing chicks due to immunological stress. Journal of Nutrition, 118 : 1158-1164. 1988.

14) Nakamura K, Mitarai $Y$, Yoshioka M, Koizumi N, Shibahara T, Nakajima Y. Serum levels of interleukin-6, $\alpha 1$-acid glycoprotein, and corticosterone in two week old chickens inoculated with Escherichia coli lipopolysaccharide. Poultry Science, 77 : 908911. 1998.

15) National Research Council. Nutrient Requirements of Poultry. 8 th revised ed. 35-47. National Academic Press. Washington, D.C. 1984.

16) Nauss KM, Connor AM, Kacancaugh A, Newbern $P N$. Alteration in immune function in rats caused by dietary lipotrope deficiency : effect of age. Journal of Nutrition, 112 : 2333-2341. 1982.

17) Spitzer JA, Friedman H, Newton C, Widen R, Pross $\mathrm{S}$, Klein TS. Suppressed in vitro blastogenic responsiveness of rat spleen cells after continuous infusion of endotoxin by an implanted osmotic pump. Proceeding of the Society for Experimental Biology and Medicine, $186: 21-26.1987$.

18) Takahashi K, Kaji S, Akiba $Y$, Tamura K. Plasma alpha 1-acid glycoprotein concentration in broilers. influence of age, sex and Escherichia coli lipopolysaccharide. British Poultry Science, 35 : 427432. 1994.

19) Takahashi K, Miyake N, Ohta T, Akiba Y, Tamura $\mathrm{K}$. Changes in plasma $\alpha 1$-acid glycoprotein concentration and selected immune response in broiler chickens injected with Escherichia coli lipopolysaccharide. British Poultry Science, 39 : 152155. 1998.

20) Takahashi $\mathbf{K}$, Ohta $T$, Akiba $Y$. Influences of dietary methionine and cysteine on metabolic responses to immunological stress by Escherichia coli lipopolysaccharide injection, and mitogenic response in broiler chickens. British Journal of Nutrition, 78 : 815-821. 1997.

21) Takahashi K, Yodogawa S, Akiba $Y$, Tamura K. Effect of dietary protein concentration on responses to Escherichia coli endotoxin in broiler chickens. British Journal of Nutrition, 74 : 173-182. 1995.

22) Tsiagbe VK, Cook ME, Harper AE, Sunde ML. Efficiency of cysteine in replacing methionine in the immune responses of broiler chicks. Poultry Science, 58:1138-1146. 1987

23) Tsiagbe VK, Cook ME, Harper AE, Sunde ML. Enhanced immune responses in broiler chicks fed methionine supplemented diets. Poultry Science, 58 : 1147-1154. 1987

24) Webel DM, Johnson RW, Baker DH. Lipopolysaccharide-induced reductions in food intake do not decrease the efficiency of lysine and threonine utilization for protein accretion in chicks. Journal of Nutrition, 128 : 1760-1766. 1998. 